\title{
Comparative study of a building energy performance software (KEP-IYTE-ESS) and ANN-based building heat load estimation
}

\author{
Cihan Turhan $^{\mathrm{a}}$, Tugce Kazanasmaz ${ }^{\mathrm{b}}$, Ilknur Erlalelitepe Uygun ${ }^{\mathrm{b}}$, \\ Kenan Evren Ekmen ${ }^{\mathrm{a}}$, Gulden Gokcen Akkurt ${ }^{\mathrm{a}, *}$ \\ a Energy Engineering Program, Izmir Institute of Technology, Gulbahce Campus, 35437 Urla, Izmir, Turkey \\ ${ }^{\mathrm{b}}$ Faculty of Architecture, Izmir Institute of Technology, Gulbahce Campus, 35437 Urla, Izmir, Turkey
}

\section{A R T I C L E I N F O}

\section{Article history:}

Received 10 June 2014

Received in revised form 1 September 2014

Accepted 13 September 2014

Available online 22 September 2014

\section{Keywords:}

Artificial neural networks

Heat load

Residential buildings

Prediction

Existing buildings

Simulation software

\begin{abstract}
A B S T R A C T
The several parameters affect the heat load of a building; geometry, construction, layout, climate and the users. These parameters are complex and interrelated. Comprehensive models are needed to understand relationships among the parameters that can handle non-linearities. The aim of this study is to predict heat load of existing buildings benefiting from width/length ratio, wall overall heat transfer coefficient, area/volume ratio, total external surface area, total window area/total external surface area ratio by using artificial neural networks and compare the results with a building energy simulation tool called KEP-IYTE-ESS developed by Izmir Institute of Technology. A back propagation neural network algorithm has been preferred and both simulation tools were applied to 148 residential buildings selected from 3 municipalities of Izmir-Turkey. Under the given conditions, a good coherence was observed between artificial neural network and building energy simulation tool results with a mean absolute percentage error of 5.06\% and successful prediction rate of 0.977 . The advantages of ANN model over the energy simulation software are observed as the simplicity, the speed of calculation and learning from the limited data sets.
\end{abstract}

(C) 2014 Elsevier B.V. All rights reserved.

\section{Introduction}

The heat load of a building is the amount of energy required to raise and maintain the temperature of the structure to the desired level. Since the energy consumption of the buildings is highly related with the heat load, determining the heat load parameters which can reduce the energy consumption of the buildings is crucial [1]. The amount of heat load for a certain level of thermal comfort depends on the building characteristics and the climate parameters. The most significant parameters to be taken into consideration are expected to be: thermo-physical properties of each material used to construct the building envelope, infiltration rate of the building components, heat gain parameters such as window solar transmissivity, internal gain by apparatus used in the building and the occupants, climate data such as solar intensity and wind speed. The determination of the building heat load requires complex correlations between those parameters and the parameters are interrelated. Therefore, comprehensive models are needed to

\footnotetext{
* Corresponding author. Tel.: +90 232750 6706; fax: +90 2327506701 .

E-mail addresses: guldengokcen@iyte.edu.tr, guldengokcen@yahoo.com (G.G. Akkurt).
}

understand relationships among these parameters that can handle non-linearities among the parameters.

There are several ways to model heat load of a building to be able to evaluate the final energy consumption of that building, varying from simple regression to dynamic analysis such as EnergyPlus [2] and DOE-2 [3] which are based on physical principles.

The regression models have been widely used in predicting heat load, cooling load and energy consumption of a building, are successful in prediction, since the values obtained by the models are well matched with the measured data and/or dynamic building energy simulation models [4-10]. Hygh et al. [9] implemented multi-variated linear regression model for an existing building based on 27 building parameters including orientation, aspect ratio, window to wall ratio and shading projection. The authors compared the results with EnergyPlus and indicated a good fit exceeded $96 \%$ of correlation coefficient $\left(R^{2}\right)$. Also, sensitivity analysis showed that building area and window to wall ratio have the largest influence on total energy consumption. Catalina et al. [10] conducted a comparative study of multiple regression model and the energy certification calculation with a detailed error analysis. A multiple regression model was selected for the prediction of heating energy demand to get rid of complexity of dynamic models. The model showed a great accuracy with correlation coefficient of 0.98 . 
Although regression models are good in accuracy, they require significant effort and time [11]. Therefore, evaluation, estimation and prediction are often done using statistical software such as SAS [12] and SPSS [13]. Most of these software are based on conventional algorithms such as the least square method, moving average, time series and curve fitting. The performances of these algorithms are not robust enough when the data set becomes very large [14].

Since the late 1990s, various dynamic building energy simulation tools such as DOE-2, EnergyPlus, TRNSYS, BDA, ESP-r, BLAST, Bsim2000, IDA [2,3,15-20] which are considered to be the most reliable solutions to estimate the impact of building parameters on the heat load have been developed. These tools are widely used for analyzing energy consumption and determining heat load of the buildings [21-26]. Boyano et al. [25] studied energy demand and potential savings in buildings based on simulation results. Many building characteristics such as orientation, overall heat transfer coefficient of the external walls and the insulation of the windows were investigated in order to decrease heat load and energy consumption. Katafygiotou and Serghides [26] examined different retrofitting scenarios for potential energy savings using the results of simulations.

A number of studies [27-29] proposed a comparison between building energy dynamic software and building energy measurements. Maile et al. [27] developed a method to compare measured and simulated data for identifying the energy performance problems with a detailed analysis using the root-mean-squared error (RMSE) and the mean bias error (MBE). Karlson et al. [28] compared measured and simulated values for a Swedish lowenergy house. The annual predicted total energy demand using three different dynamic simulation software deviated by about $2 \%$.

Dynamic building simulation tools are good in accuracy when obtained the required number of and the precise input data which is possible only for the buildings have architectural projects [4].

Artificial Neural Networks (ANNs) have accepted as an alternative technology offering a way to tackle complex and ill-defined problems and to give accurate results with a limited number of data since 1990s. They are not programmed in the traditional way but they are trained using past history data representing the behaviour of a system [14]. ANNs can be defined as the learning, understanding and thinking ability of computers [10] that have been widely used for a range of applications in the area of energy modelling [11,30-37]. Several studies published on predicting energy consumption, cooling load and heat load of buildings using ANN methods [23,30-33]. Ekici and Aksoy [31] implemented ANNs for prediction of building energy consumption in Turkey. The main objective of the study was to predict buildings energy needs based on orientation, insulation thickness and transparency. A computer program written in FORTRAN [38] was used for the calculations of energy demand and ANN toolbox of MATLAB [39] was selected for predictions. As a conclusion; when the calculated values compared with the outputs of the network, it was proven that ANN gives satisfactory results with deviation of $3.43 \%$ and successful prediction rate of 94.8-98.5\%. Mavromatidis et al. [32] implemented an ANN model for prediction of energy performance of a supermarket building. Day of the week, hour of the day, external temperature and store average temperature were selected as input variables. The results indicated a remarkable accuracy for calculating energy performance with a correlation coefficient $\left(R^{2}\right)$ of 0.98 and the mean absolute error (MAE) of 4.79. Kwok et al. [33] was used ANN to estimate the cooling load of a building. The training samples were taken from the Hong Kong Observatory and building-related data acquired from an existing office building in Hong Kong with tenants including many multi-national financial companies that require 24$\mathrm{h}$ air conditioning seven days a week. The results presented that the occupancy area and rate were the highest effect on the building cooling load.

Various authors $[23,30,36,40]$ performed a comparison of ANN models with building dynamic simulation software. Neto and Fiorelli [23] presented a comparison of ANN with a physical simulation tool as EnergyPlus. In this study, climate variables such as relative humidity, external dry-bulb temperature and solar radiation were used as input variables in order to predict daily energy consumption of the building. The results showed that ANN model results fairly agree with the simulated data. Melo et al. [36] presented an ANN model to improve the accuracy of surrogate models for building shell energy labelling purposes. Building properties with different areas, numbers of floor, conditioned areas and other characteristics were taken into account for the construction of the model. The results were compared with the EnergyPlus simulation results. The model indicated that the facade area and the shell to floor ratio played a significant role in the energy performance of buildings.

Many authors [9,11,23,30,32,36,37] considered various input parameters for their models to estimate energy consumption and heat load. Hygh et al. [9] used 27 building parameters including orientation, aspect ratio and shading projection while Wong et al. [30] used external weather conditions (daily average dry-bulb temperature, daily average wet-bulb temperature, daily global solar radiation and daily average clearness index), building envelope designs (solar aperture, daylight aperture, overhang and side-fins projections) and day time (i.e. weekends, Saturdays and Sundays) as input variables. Day of the week, hour of the day, external temperature and store average temperature were selected as input variables by Mavromatidis et al. [32]. Also, Chou and Bui [37] proposed the prediction of the heating and cooling load of buildings by ANNs with 8 inputs (relative compactness, surface area, wall area, roof area, overall height, orientation, glazing area and glazing distribution).

Up to now, to the authors' knowledge few studies have been published on the heat load estimation of existing buildings.

The scope of this study is to predict the heat load of existing buildings by ANN and compare the results with a building energy simulation tool. The simulation tool used is called The Standard Assessment Procedure for Energy Rating of Dwellings software (KEP-IYTE-ESS), was developed by Izmir Institute of Technology [41]. A number of 148 existing residential buildings are used for the study.

\section{Materials and method}

A number of 148 existing residential buildings consist of 2136 apartments in Izmir-Turkey were chosen to collect data for ANN and building energy simulation model (Fig. 1).

Izmir, situated on the west cost of Turkey (latitude $38^{\circ} 25 \mathrm{~N}$, longitude $27^{\circ} 08 \mathrm{E}$ ), has a typical Mediterranean climate which is characterized as temperate-humid. The minimum average temperatures during winter vary between 6 and $8^{\circ} \mathrm{C}$. Monthly mean temperatures, however, during summer (May-October) are almost $25^{\circ} \mathrm{C}$ or higher [42]. The $40 \%$ of existing building stock in Izmir consists of 5 or higher storey residential buildings. Increasing population, lack of construction area and mass housing demand caused to this inclination in the construction of multi-storey residential buildings. Therefore, the buildings considered in this study were chosen to be 5-11 storey residential buildings. Since the municipalities of Konak, Karabağlar and Balçova have the highest rate of multi-storey buildings, they are considered as sampling sites. Construction permits, architectural and mechanical projects of the buildings were obtained from archives of Konak, Karabağlar and Balçova Municipalities (Fig. 2). 


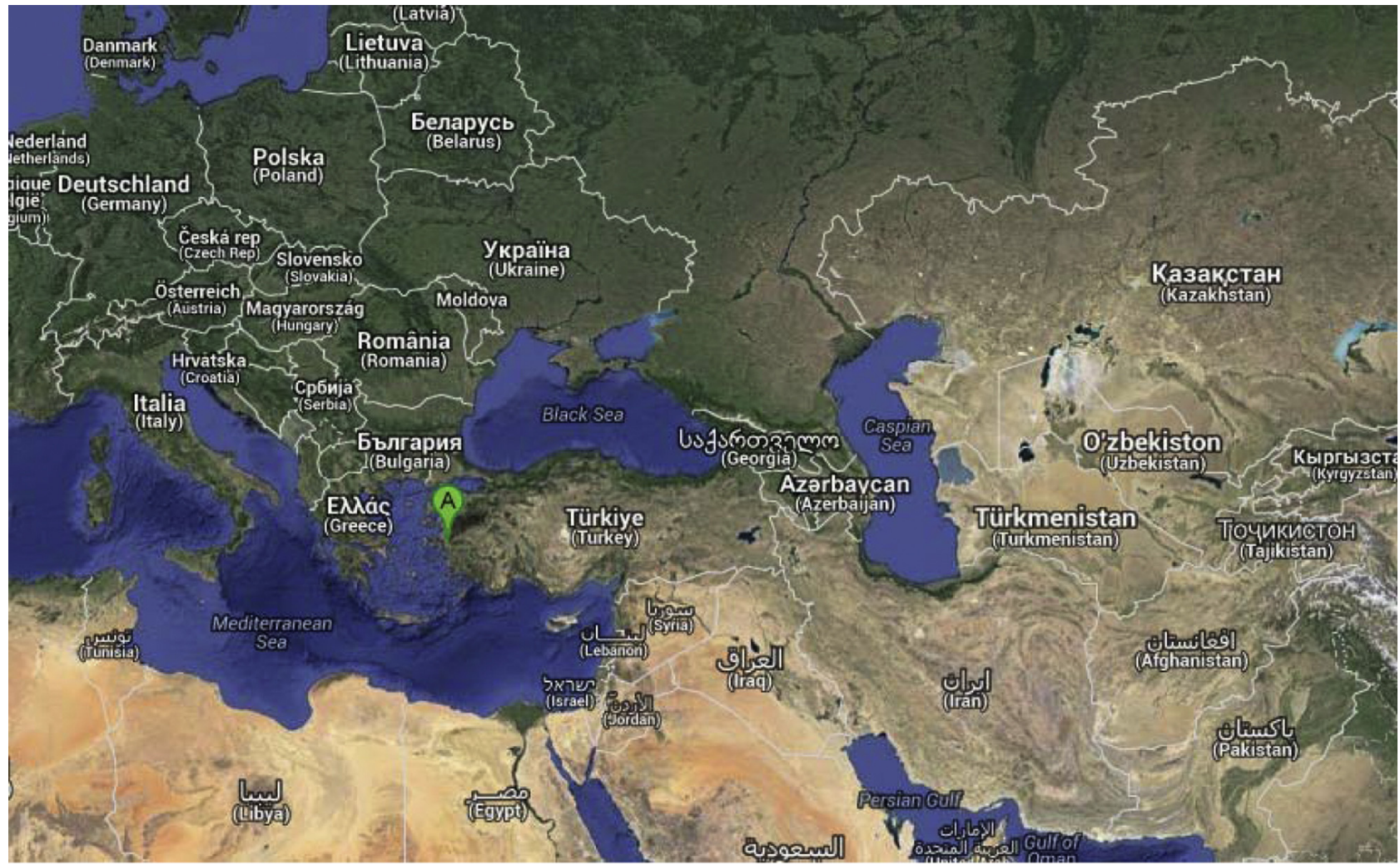

Fig. 1. Location of Izmir, Turkey.

\subsection{The building energy performance software (KEP-IYTE-ESS)}

The Standard Assessment Method for Energy Performance of Dwellings (KEP-SDM) was developed to obtain energy certificate of buildings by utilizing a calculation procedure including heating, domestic hot water production and lighting energy consumptions and greenhouse gas emissions of dwellings by the Chamber of Mechanical Engineers, Izmir Institute of Technology and Istanbul
Technical University in 2008 [41]. The method is referred to TS 825 [43] which provides a framework for the calculation of heating energy demand in buildings and European standard EN ISO 13790 [44].

According to EN ISO 13790, there are three classifications of energy performance evaluation methods: seasonal or monthly static method, simple hourly dynamic method (simple dynamic) and detailed hourly dynamic method (full dynamic). KEP-SDM is a

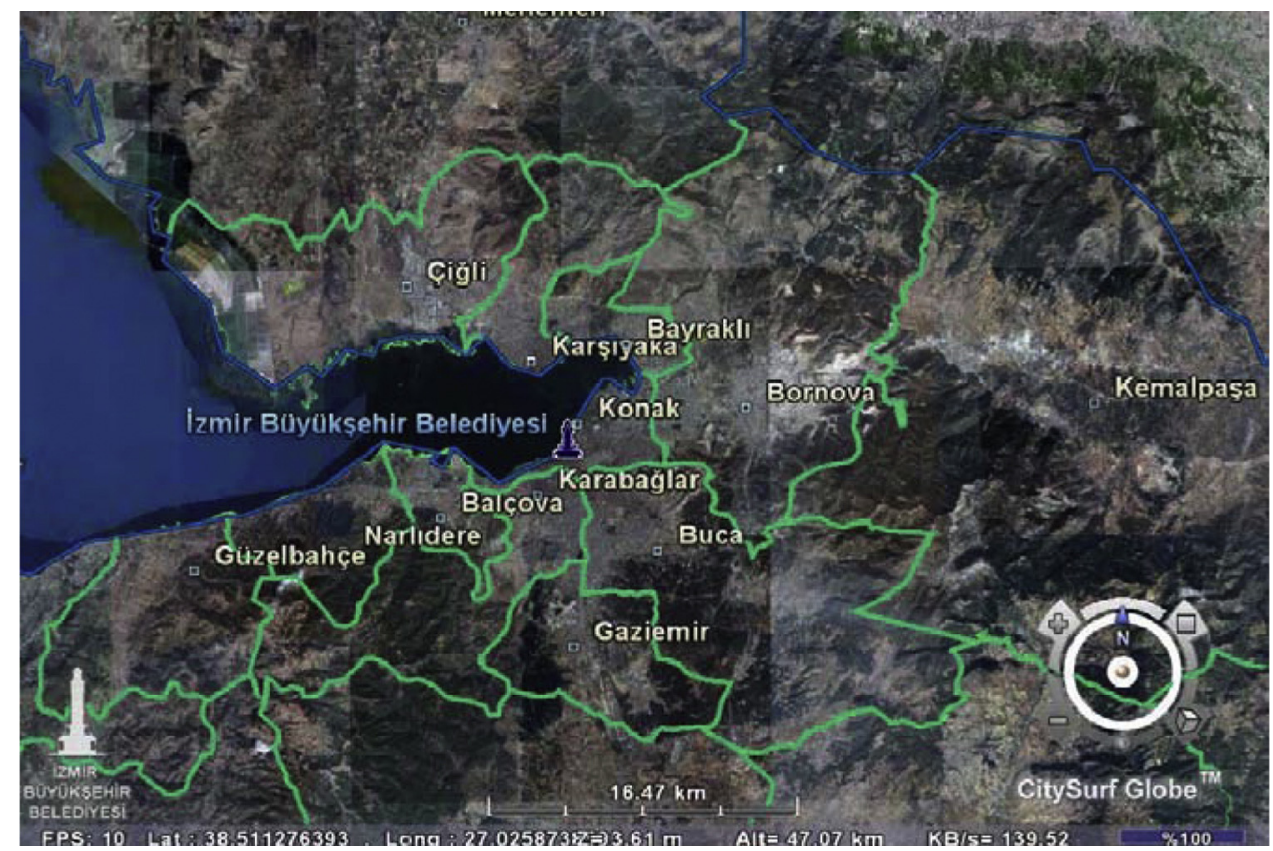

Fig. 2. Location of municipalities of Konak, Karabaglar and Balcova. 


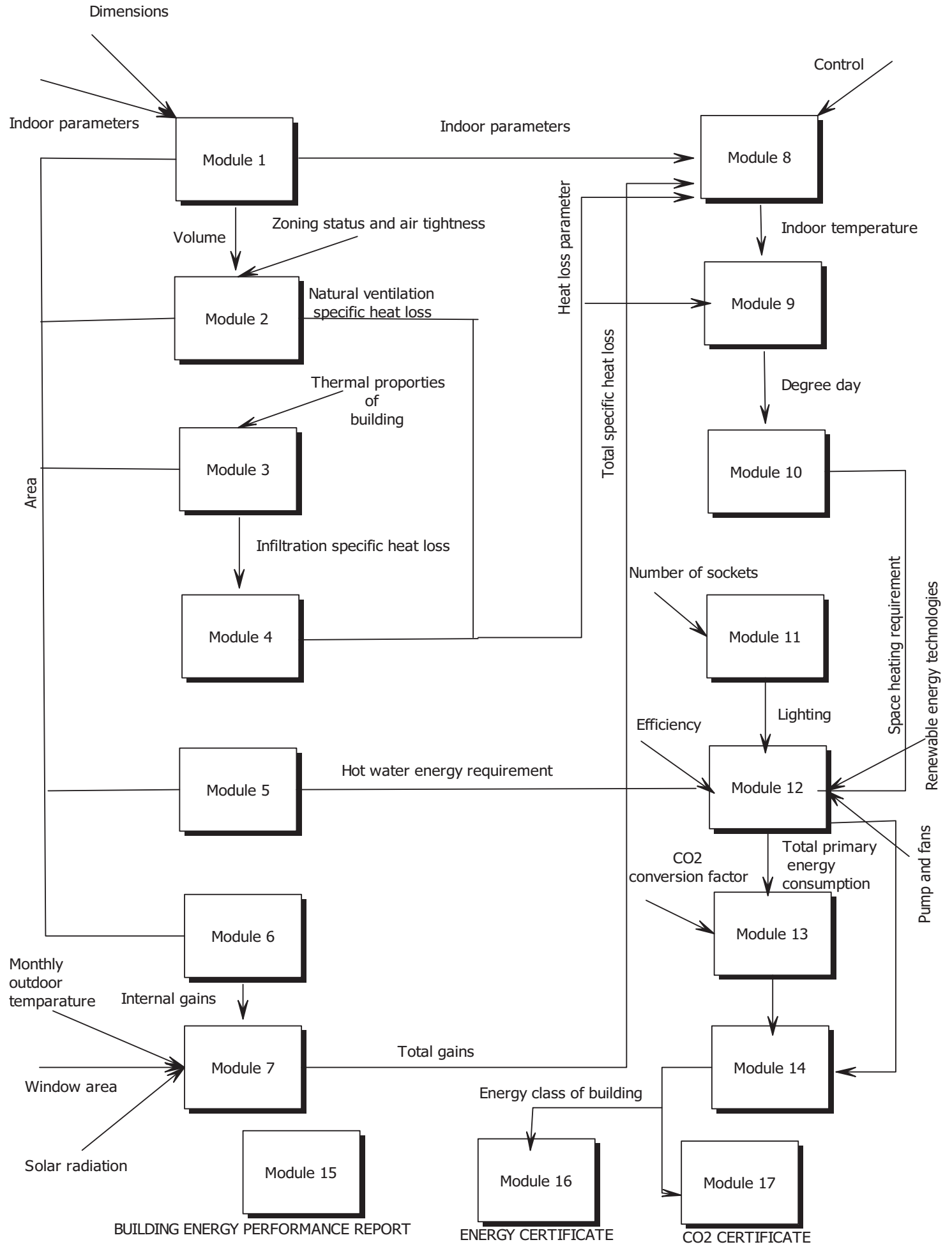

Fig. 3. KEP-IYTE-ESS energy performance calculation flow chart.

monthly method including degree-day correction. The calculation is based on the energy balance considering a range of factors which contribute to energy efficiency, as mentioned below;

- Materials used for construction of the dwelling

- Thermal insulation of the building fabric

- Ventilation characteristics of the dwelling and ventilation equipment

- Efficiency and control of the heating system(s)

- Solar gains through openings of the dwelling
- The fuel used to provide space and water heating, ventilation and lighting

- Renewable energy technologies

The calculation ignores some of the factors, as mentioned below;

- Household size and composition

- Ownership and efficiency of particular domestic electrical appliances

- Individual heating patterns and temperatures. 
KEP-IYTE-ESS is a software developed based on the KEP-SDM methodology. It describes the buildings as a single-zone but internal temperature is separated according to the living area and the rest. Furthermore, the calculation allows thermal bridges in the building unlike thermal mass of the building and weather data is taken from National Meteorological Institution for each city. The software gives the users two outputs; annual energy consumption per unit floor area $\left(\mathrm{kWh} / \mathrm{m}^{2}\right.$ year) and annual greenhouse gas emissions per unit floor area $\left(\mathrm{kg} \mathrm{CO}_{2} / \mathrm{m}^{2}\right.$ year) [41].

In order to obtain the heat load of case buildings, KEP-IYTE-ESS Software was used. The software consists of 17 calculation modules which are schematically shown in Fig. 3, as listed below;

- Dwelling dimensions and internal parameters

- Ventilation rate

- Heat losses

- Specific heat loss and heat loss parameter

- Domestic hot water

- Internal gains

- Solar gains and gain utilization factors

- Mean internal temperature

- Degree-days

- Space heating requirements

- Lighting energy requirements

- Total and primary energy consumption

- $\mathrm{CO}_{2}$ emissions

- Energy and $\mathrm{CO}_{2}$ certificates

The methodologies are reliable if they are validated. KEP-IYTEESS was tested using a well-known validation and diagnostic procedure, Building Energy Simulation Test (BESTEST) [45]. BESTEST is a procedure, which was developed by International Energy Agency (IEA) in 1995, to test and diagnose the building energy simulation programs. The procedure contains several tests assessing the effect of physical properties on the results of building energy simulations. The purpose of this procedure is to create obvious, well-defined test series for software-to-software comparisons and program diagnostics. KEP-IYTE-ESS was validated by the BESTEST procedure and the outputs were in the range of acceptable values of BESTEST [46].

\subsection{Artificial Neural Networks (ANNs)}

ANNs which are inspired from the biological nervous system are parallel-interconnected networks of simple computational elements which aim to interact with the objects of the real world. A neuron is the fundamental cellular unit of nervous system. It is a very simple processing element which receives and combines signals from the other neurons through input paths called dendrites. If the combined input signal is strong enough, the neuron fires producing an output signal along the axon that connects to the dendrites of many other neurons. An artificial neuron is a model whose components have directly analogues to components of an actual neuron. Fig. 4 shows the basic architecture of the network which consists of dendrites, axon and synapse and artificial neuron [47].

Processing elements in the architecture of the model are usually organized into an order of layers with full or random connections between the layers. Input layer presents data to the network. This layer is not a neural computing layer since the nodes have no weights or activation functions. Output layer presents the output response to a given input. The other layer (or layers) is called hidden layer (or intermediate layer) since it has no connections to the outside world. An example of a neural network for this study is shown in Fig. 5.

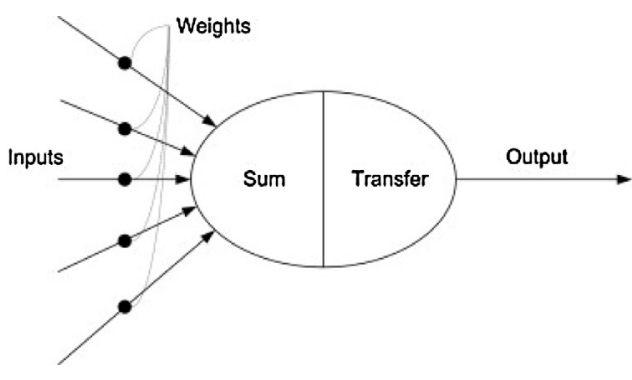

Fig. 4. Representation of an artificial neuron.

Scalar input $x_{1}, x_{2}, \ldots, x_{n}$ are multiplied by weights $w_{1 j}, w_{2 j}, \ldots$, $w_{n j}$ and the weighted values are fed to the summing confluence. The neuron has a bias $b_{i}$ that is summed with the weighted inputs in order to form the net input net ${ }_{j}$ given in Eq. (1).

net $_{j}=x_{1} w_{1 j}+x_{2} w_{2 j}+\ldots \ldots+x_{n} w_{n j}+b_{i}$

Net input is the argument of the transfer function $f$. Therefore, the output value obtained is given in Eq. (2).

$o_{j}=f\left(\right.$ net $\left._{j}\right)$

The most frequently used transfer function is sigmoid transfer function. This function can range between 0 and 1 , but it is also sometimes useful to use the -1 to 1 range [31]. An ANN is usually composed of an input layer, some hidden layers, and an output layer. The knowledge that underlies processing is generally stored as connection weights.

In the training phase of ANN, model modifies the connection weights using a suitable learning method. The network uses a learning mode, in which an input is presented to the network along with the desired output and weights are adjusted so that the network attempts to produce the desired output. Afterwards, error value is calculated from the difference between the network's output and the expected output. Reputation conducted to decrease error to an acceptable value that is called epoch or training cycle [30]. The error is expressed by the root-mean-squared error value (RMSE), which can be calculated with following equation:

$E=\frac{1}{2}\left[\sum_{p} \sum_{i}\left|t_{i p}-o_{i p}\right|\right]^{1 / 2}$

where $(E)$ is the RMSE, $t$ the network output, and $o$ the desired output vectors over all the pattern $(p)$. An error of zero would indicate all the output values computed by the ANN perfectly match the expected values and the network is well trained. Back propagation training is done by giving random values to weights of all nodes. The variation quantity of the weight of the connection can be calculated with Eq. (4):

$\Delta w_{j m}(t)=\lambda \delta_{m} o_{j}+\alpha \Delta w_{j m}(t-1)$

where $\lambda$ is the training rate, $\alpha$ is the momentum coefficient and $\delta_{m}$ is the error of the $m$ th output layer calculated with Eq. (5):

$\delta_{m}=o_{m}\left(1-o_{m}\right) E_{m}$

\subsection{ANN model parameters}

The model input parameters were chosen as measurable parameters in case that architectural projects of the buildings are not available such as width/length ratio, wall overall heat transfer coefficient, area/volume ratio, total external surface area, total window area/total external surface area ratio. 


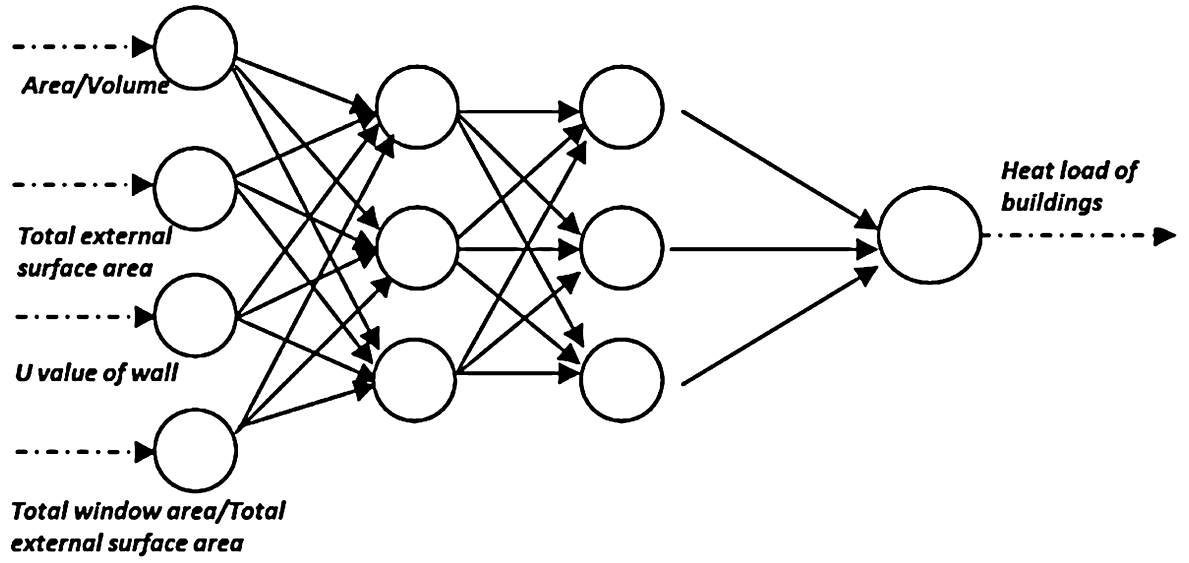

\section{Input layer Hidden layer Output layer}

Fig. 5. Example of neural network architecture.

\subsubsection{Width/length $(W / L)$ ratio (-)}

The $W / L$ ratio is an indicator of plan configuration. The objective is to determine maximum utility spaces and building surfaces in suggested zoning plan. The ratio is one of the main factors that determine the relationship between solar gain and heat load. The studies on $\mathrm{W} / \mathrm{L}$ ratio have showed that, maximum elongation in east-west axis (1:2) is preferable in hot climates while (1:1.2) turns out to be the optimum case for cold climates [48].

\subsubsection{Wall overall heat transfer coefficient $(U)\left(W / m^{2} K\right)$}

The $U$ value used to calculate the total heat transfer through a wall, depends on the thermo-physical properties of air on both sides of the wall, and the properties of the wall components and the transparent surfaces. Decreasing wall overall heat transfer coefficient minimizes the total energy consumption of buildings [49].

\subsubsection{Area/volume $(\mathrm{A} / \mathrm{V})$ ratio $\left(\mathrm{m}^{2} / \mathrm{m}^{3}\right)$}

$\mathrm{A} / \mathrm{V}$ ratio of a building is an important factor determining the heat loss/gain of the building. The greater the surface area, the higher the heat gain/loss through it. Therefore, small A/V ratios imply minimum heat gain and minimum heat loss [50].

\subsubsection{Total external surface area $\left(\mathrm{m}^{2}\right)$}

Total external surface area is calculated from external perimeter and the floor to ceiling height of a building. Increasing the surface area, increases the energy consumption [49].

\subsubsection{Total window area/total external surface area (TWA/TESA) ratio $(-)$}

TWA/TESA ratio is viewed as the indicator for the equilibrium of solid-void, describing effects of void surfaces to hold minimum heat load. The relatively low insulation levels afforded by windows will have an impact on the internal thermal performance of a building during the winter, while larger windows will increase internal solar heat gains [50].

Log-sigmoid transfer function which is widely used for transfer function was selected in the hidden layer and output layer. The function is shown in Eq. (6) [51].

$y=\frac{1}{1+e^{- \text {net }}}$

The commonly used statistical criteria, mean squared error (MSE), correlation coefficient $\left(R^{2}\right)$ and mean absolute percentage error (MAPE) were calculated for each model. While the $R^{2}$ is expected to be close to 1, MAPE and MSE should be as close as to zero $[14,32]$.

$$
\begin{aligned}
& \text { MSE }=\frac{1}{p} \sum\left|t_{j}-o_{j}\right|^{2} \\
& R^{2}=1-\left(\frac{\sum_{j}\left|t_{j}-o_{j}\right|^{2}}{\sum_{j}\left(o_{j}\right)^{2}}\right) \\
& \text { MAPE }=\frac{1}{p} \sum_{j}\left[\left|\frac{t_{j}-o_{j}}{t_{j}}\right|\right] \times 100
\end{aligned}
$$

$t$ is the target value, $o$ is the output value and $p$ is the number of input-output pairs [52].

\subsection{Sensitivity analysis}

Sensitivity analysis investigates the model feedbacks, evaluates the accuracy of model and tests the cogency of the assumption made in engineering design stage [53]. The mapping $Y=f(X)$ between an output $Y$ of a computational model and a set of uncertain input factors $X=\left(X_{1}, \ldots, X_{k}\right)$ is analysed in order to quantify the relative contribution of each input factor to the uncertainty of $Y[54]$.Sensitivity is used to find the rate of change in a model output due to changes in the model inputs in deterministic design, which is usually performed by partial derivative analytically or numerically. By employing sensitivity analysis on a trained network, some irrelevant inputs can be found and then eliminated. Therefore, such an elimination of irrelevant inputs can sometimes improve a network's performance. This batch starts by varying the first input

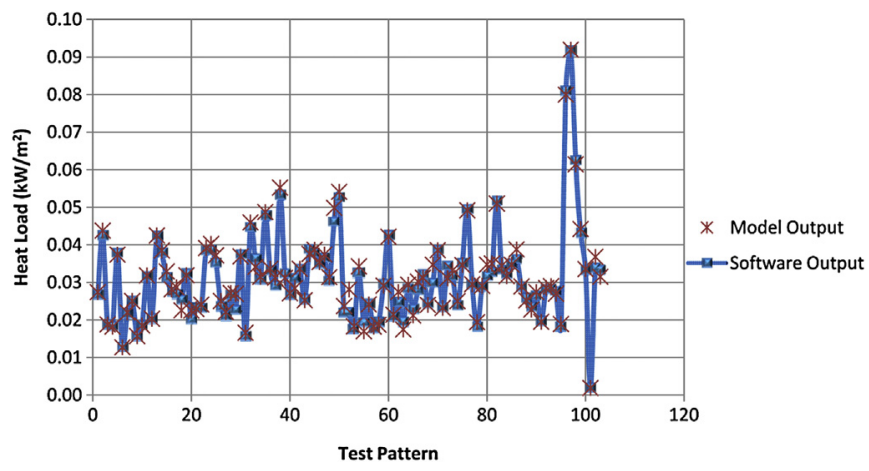

Fig. 6. Training results and their comparisons with the simulated values. 
Table 1

The input parameters used in the model construction.

\begin{tabular}{|c|c|c|c|}
\hline \multirow[t]{2}{*}{ Code } & \multirow[t]{2}{*}{ Input parameters } & \multicolumn{2}{|c|}{ Data used in ANN models } \\
\hline & & Minimum & Maximum \\
\hline$x_{1}$ & Width/length & 0.2125 & 1 \\
\hline$x_{2}$ & Wall overall heat transfer coefficient $\left(\mathrm{W} / \mathrm{m}^{2} \mathrm{~K}\right)$ & 0.43 & 1.83 \\
\hline$x_{3}$ & Area/volume & 0.0579 & 0.6404 \\
\hline$x_{4}$ & Total external surface area (m) & 208.44 & 2655.82 \\
\hline$x_{5}$ & Total window area/total external surface area & 0.1048 & 0.6348 \\
\hline$y_{1}$ & Heat load $\left(\mathrm{kW} / \mathrm{m}^{2}\right)$ & 0.0019 & 0.0918 \\
\hline
\end{tabular}

Table 2

Statistical data obtained using different structures for the heat load of buildings.

\begin{tabular}{|c|c|c|c|c|c|c|c|}
\hline \multirow[t]{2}{*}{ Learning algorithm } & \multirow[t]{2}{*}{ Number of Neurons } & \multicolumn{3}{|l|}{ Training Set } & \multicolumn{3}{|l|}{ Testing Set } \\
\hline & & MSE & $R^{2}$ & MAPE & MSE & $R^{2}$ & MAPE \\
\hline LM & $5-3-1$ & $7.27 \times 10^{-6}$ & 0.956 & 5.08 & $2.79 \times 10^{-5}$ & 0.939 & 8.8 \\
\hline LM & $5-5-1$ & $1.06 \times 10^{-5}$ & 0.948 & 8.46 & $3.52 \times 10^{-5}$ & 0.936 & 10.81 \\
\hline LM & $5-7-1$ & $1.95 \times 10^{-5}$ & 0.939 & 8.92 & $3.90 \times 10^{-5}$ & 0.93 & 11.06 \\
\hline LM & $5-9-1$ & $1.41 \times 10^{-5}$ & 0.926 & 10.72 & $5.25 \times 10^{-5}$ & 0.915 & 11.69 \\
\hline LM & $5-3-1-1$ & $7.20 \times 10^{-6}$ & 0.958 & 5.04 & $2.79 \times 10^{-5}$ & 0.94 & 8.7 \\
\hline LM & $5-3-3-1$ & $1.04 \times 10^{-5}$ & 0.949 & 8.44 & $3.50 \times 10^{-5}$ & 0.938 & 10.79 \\
\hline LM & $5-5-3-1$ & $1.01 \times 10^{-5}$ & 0.951 & 7.09 & $3.08 \times 10^{-5}$ & 0.939 & 10.65 \\
\hline LM & $5-5-5-1$ & $1.22 \times 10^{-5}$ & 0.95 & 7.11 & $3.01 \times 10^{-5}$ & 0.939 & 10.61 \\
\hline LM & $5-7-3-1$ & $1.61 \times 10^{-5}$ & 0.941 & 8.4 & $3.42 \times 10^{-5}$ & 0.932 & 11.01 \\
\hline LM & $5-7-5-1$ & $1.45 \times 10^{-5}$ & 0.945 & 8.1 & $3.56 \times 10^{-5}$ & 0.937 & 10.85 \\
\hline LM & $5-7-7-1$ & $1.55 \times 10^{-5}$ & 0.941 & 8.5 & $3.51 \times 10^{-5}$ & 0.931 & 10.8 \\
\hline LM & $5-9-3-1$ & $1.25 \times 10^{-5}$ & 0.935 & 10.05 & $5.28 \times 10^{-5}$ & 0.919 & 11.61 \\
\hline LM & $5-9-5-1$ & $1.18 \times 10^{-5}$ & 0.94 & 9.97 & $5.02 \times 10^{-5}$ & 0.928 & 10.85 \\
\hline LM & $5-9-7-1$ & $1.35 \times 10^{-5}$ & 0.935 & 10.1 & $5.01 \times 10^{-5}$ & 0.92 & 10.79 \\
\hline LM & $4-3-1$ & $3.67 \times 10^{-6}$ & 0.976 & 4.55 & $2.39 \times 10^{-5}$ & 0.947 & 8.48 \\
\hline LM & $4-5-1$ & $4.22 \times 10^{-6}$ & 0.974 & 5.39 & $2.49 \times 10^{-5}$ & 0.946 & 8.43 \\
\hline LM & $4-7-1$ & $2.99 \times 10^{-6}$ & 0.982 & 4.54 & $1.13 \times 10^{-5}$ & 0.975 & 5.89 \\
\hline LM & $4-9-1$ & $4.86 \times 10^{-6}$ & 0.97 & 6.08 & $2.40 \times 10^{-5}$ & 0.947 & 9.6 \\
\hline LM & $4-3-1-1$ & $3.60 \times 10^{-6}$ & 0.978 & 4.54 & $2.31 \times 10^{-5}$ & 0.948 & 8.41 \\
\hline LM & $4-3-3-1$ & $3.65 \times 10^{-6}$ & 0.976 & 4.55 & $2.30 \times 10^{-5}$ & 0.947 & 8.42 \\
\hline LM & $4-5-3-1$ & $4.20 \times 10^{-6}$ & 0.976 & 5.31 & $2.41 \times 10^{-5}$ & 0.948 & 8.39 \\
\hline LM & $4-5-5-1$ & $4.71 \times 10^{-6}$ & 0.971 & 5.4 & $2.58 \times 10^{-5}$ & 0.941 & 8.51 \\
\hline LM & $4-7-3-1$ & $2.56 \times 10^{-6}$ & 0.984 & 4.11 & $1.18 \times 10^{-5}$ & 0.976 & 5.16 \\
\hline LM & $4-7-5-1$ & $2.49 \times 10^{-6}$ & 0.985 & 4 & $1.03 \times 10^{-5}$ & 0.977 & 5.06 \\
\hline LM & $4-7-7-1$ & $2.70 \times 10^{-6}$ & 0.983 & 4.38 & $1.20 \times 10^{-5}$ & 0.976 & 5.19 \\
\hline LM & $4-9-5-1$ & $4.80 \times 10^{-6}$ & 0.971 & 6.01 & $2.25 \times 10^{-5}$ & 0.949 & 9.4 \\
\hline LM & $4-9-7-1$ & $4.75 \times 10^{-6}$ & 0.973 & 5.98 & $2.20 \times 10^{-5}$ & 0.95 & 9.35 \\
\hline SCG & $5-3-1$ & $6.99 \times 10^{-6}$ & 0.956 & 7.43 & $2.97 \times 10^{-5}$ & 0.933 & 10.75 \\
\hline SCG & $5-5-1$ & $9.40 \times 10^{-6}$ & 0.949 & 8.19 & $3.36 \times 10^{-5}$ & 0.938 & 10.42 \\
\hline SCG & $5-7-1$ & $1.15 \times 10^{-5}$ & 0.934 & 9.47 & $4.10 \times 10^{-5}$ & 0.926 & 12.08 \\
\hline SCG & $5-9-1$ & $1.32 \times 10^{-5}$ & 0.926 & 10.62 & $4.56 \times 10^{-5}$ & 0.919 & 12.85 \\
\hline SCG & $5-3-1-1$ & $6.90 \times 10^{-6}$ & 0.959 & 7.4 & $2.91 \times 10^{-5}$ & 0.934 & 10.6 \\
\hline SCG & $5-3-3-1$ & $6.45 \times 10^{-6}$ & 0.961 & 7.1 & $2.78 \times 10^{-5}$ & 0.939 & 10.1 \\
\hline SCG & $5-5-3-1$ & $9.25 \times 10^{-6}$ & 0.952 & 8.01 & $3.30 \times 10^{-5}$ & 0.939 & 10.35 \\
\hline SCG & $5-5-5-1$ & $9.30 \times 10^{-6}$ & 0.951 & 8.08 & $3.35 \times 10^{-5}$ & 0.937 & 10.48 \\
\hline SCG & $5-7-3-1$ & $1.10 \times 10^{-5}$ & 0.936 & 9.38 & $4.02 \times 10^{-5}$ & 0.929 & 11.98 \\
\hline SCG & $5-7-5-1$ & $1.01 \times 10^{-5}$ & 0.938 & 9.29 & $4.00 \times 10^{-5}$ & 0.93 & 11.85 \\
\hline SCG & $5-7-7-1$ & $1.09 \times 10^{-5}$ & 0.936 & 9.35 & $4.02 \times 10^{-5}$ & 0.928 & 11.97 \\
\hline SCG & $5-9-3-1$ & $1.30 \times 10^{-5}$ & 0.929 & 10.59 & $4.50 \times 10^{-5}$ & 0.92 & 12.76 \\
\hline SCG & $5-9-5-1$ & $1.21 \times 10^{-5}$ & 0.931 & 10.05 & $4.48 \times 10^{-5}$ & 0.924 & 12.42 \\
\hline SCG & $5-9-7-1$ & $1.29 \times 10^{-5}$ & 0.93 & 10.11 & $4.56 \times 10^{-5}$ & 0.92 & 12.7 \\
\hline SCG & $4-3-1$ & $5.16 \times 10^{-6}$ & 0.967 & 5.84 & $2.48 \times 10^{-5}$ & 0.946 & 8.55 \\
\hline SCG & $4-5-1$ & $4.27 \times 10^{-6}$ & 0.973 & 5.53 & $2.65 \times 10^{-5}$ & 0.942 & 8.54 \\
\hline SCG & $4-7-1$ & $4.00 \times 10^{-6}$ & 0.975 & 5.29 & $1.41 \times 10^{-5}$ & 0.968 & 7.11 \\
\hline SCG & $4-9-1$ & $5.66 \times 10^{-6}$ & 0.964 & 6.47 & $2.58 \times 10^{-5}$ & 0.942 & 9.69 \\
\hline SCG & $4-3-1-1$ & $5.15 \times 10^{-6}$ & 0.967 & 5.81 & $2.46 \times 10^{-5}$ & 0.946 & 8.52 \\
\hline SCG & $4-3-3-1$ & $5.02 \times 10^{-6}$ & 0.97 & 5.69 & $2.34 \times 10^{-5}$ & 0.954 & 7.98 \\
\hline SCG & $4-5-3-1$ & $4.11 \times 10^{-6}$ & 0.975 & 5.47 & $2.60 \times 10^{-5}$ & 0.945 & 8.51 \\
\hline SCG & $4-5-5-1$ & $4.21 \times 10^{-6}$ & 0.974 & 5.49 & $2.51 \times 10^{-5}$ & 0.944 & 8.48 \\
\hline SCG & $4-7-3-1$ & $3.95 \times 10^{-6}$ & 0.975 & 5.31 & $1.40 \times 10^{-5}$ & 0.969 & 7.1 \\
\hline SCG & $4-7-5-1$ & $3.68 \times 10^{-6}$ & 0.977 & 5.25 & $1.40 \times 10^{-5}$ & 0.97 & 6.98 \\
\hline SCG & $4-7-7-1$ & $3.71 \times 10^{-6}$ & 0.976 & 5.29 & $1.45 \times 10^{-5}$ & 0.969 & 7.02 \\
\hline SCG & $4-9-5-1$ & $5.57 \times 10^{-6}$ & 0.968 & 6.4 & $2.50 \times 10^{-5}$ & 0.949 & 9.61 \\
\hline SCG & $4-9-7-1$ & $5.54 \times 10^{-6}$ & 0.969 & 6.24 & $2.39 \times 10^{-5}$ & 0.951 & 9.58 \\
\hline
\end{tabular}

The best ANN model was shown with bold characters in the table. 


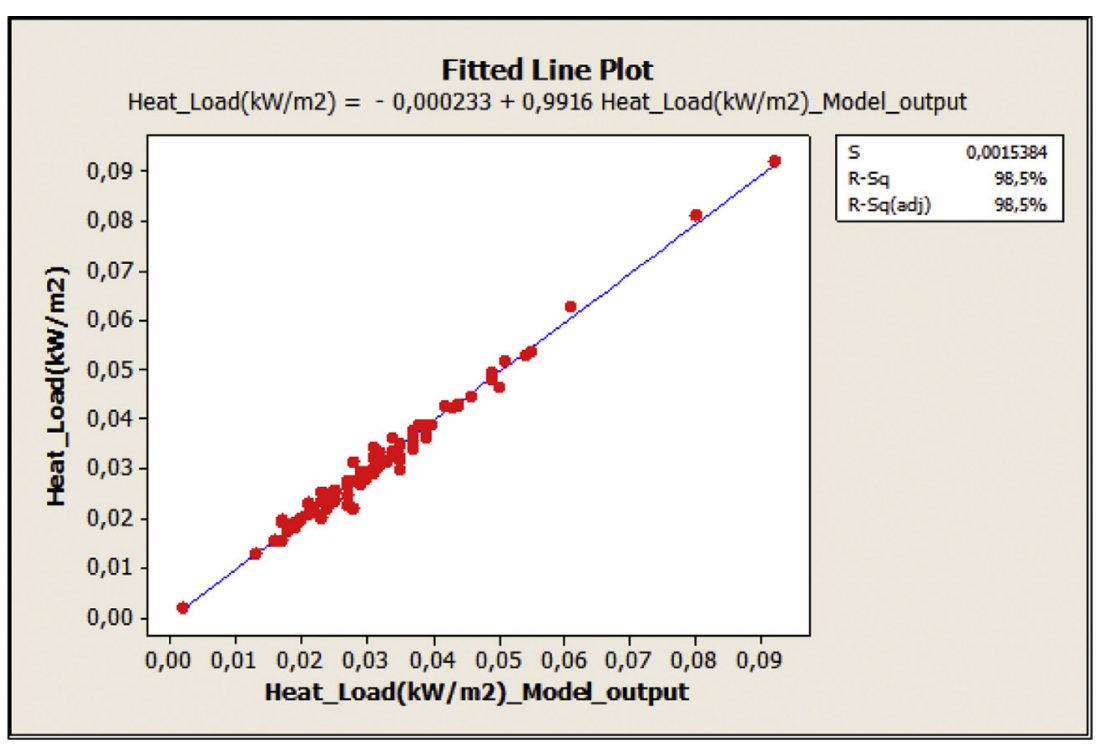

Fig. 7. The statistical evaluation of ANN and simulation results for training set.

between its mean \pm a user defined number of standard deviations while all other inputs are fixed at their respective means. The network output is computed for a user defined number of steps above and below the mean. This process is then repeated for each input. Finally, a sensitivity analysis report is generated which summarizes the variation of each output with respect to the variation of each input [53].

The models were subjected to sensitivity analysis to determine the effect of each input variable on the model output [54].

\section{Results and discussion}

\subsection{ANN model}

ANN model of existing residential buildings was developed for 5 input parameters which were $\mathrm{W} / \mathrm{L}$ ratio, wall overall heat transfer coefficient, A/V ratio, total external surface area and TWA/TESA ratio. The output parameter was the heat load of the buildings. The input data was compiled from a total number of 148 residential building including 2136 apartments situated in three different municipalities of Izmir-Turkey.

The maximum and minimum values of 5 input parameters are listed in Table 1. In the ANN model, 103 of total 148 building data were used for training and the remaining 45 building data were used for testing.

The developed ANN model contains 20.000 iterations which were found adequate for the final training.

Levenberg-Marquardt (LM) learning algorithm that is variant of feed-forward back-propagation and Scaled Conjugate Gradient (SCG) that is variant of supervised learning algorithm were used in the model while no bias terms were used. A number of network structures with single and double hidden layers, various numbers of neurons in the hidden layers were used in determining the optimal training parameters for the performance values of heat load of the

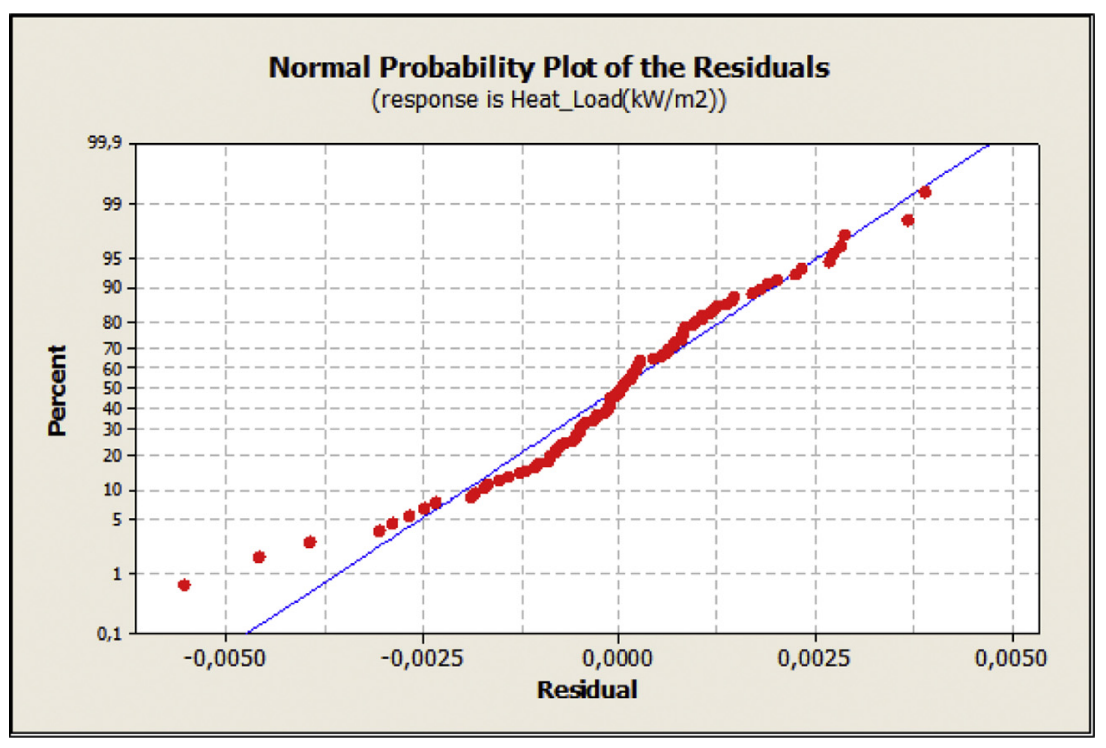

Fig. 8. Normal probability plot of the residuals for training set. 


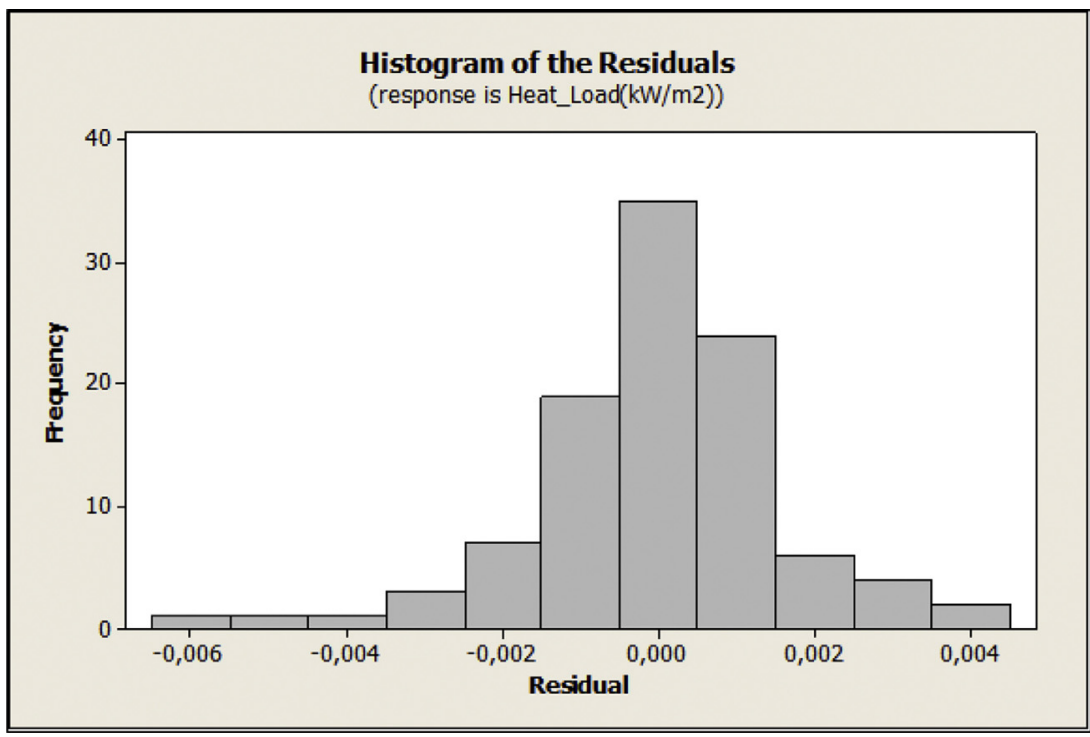

Fig. 9. The histogram of residuals of ANN for training set.

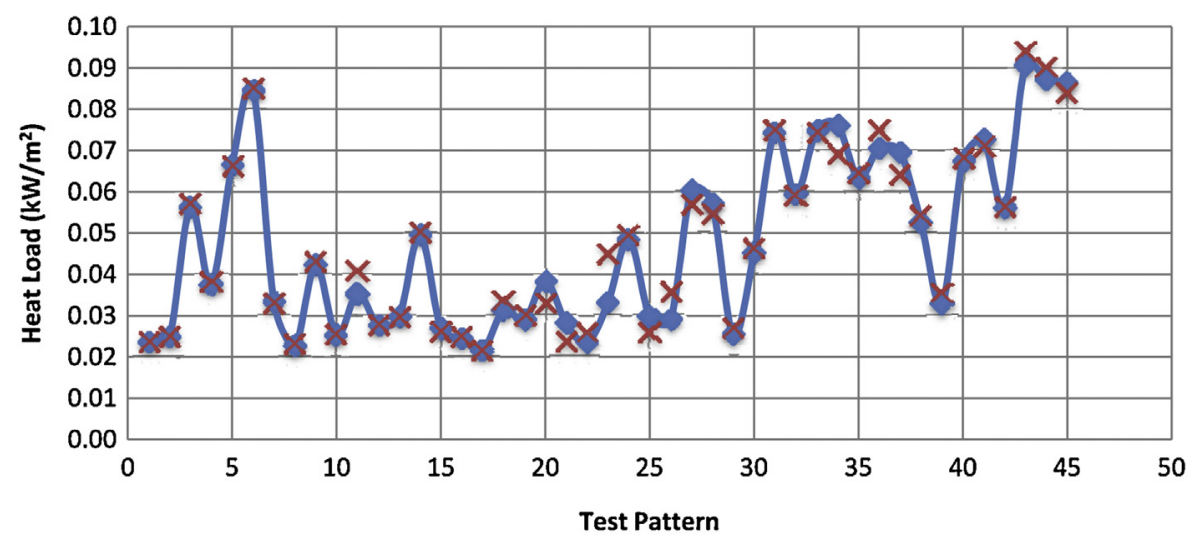

$\longrightarrow$ Software Output $\times$ Model Output

Fig. 10. Test results and their comparisons with the simulated values.

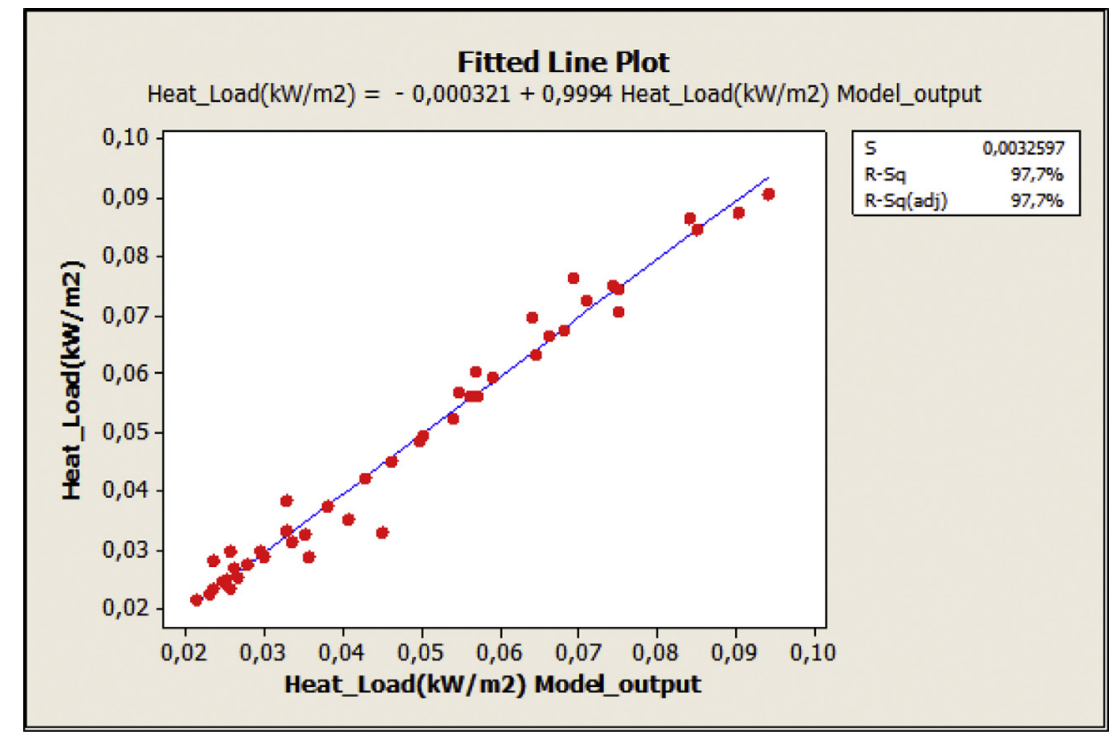

Fig. 11. The statistical evaluation of ANN and simulation results for testing set. 


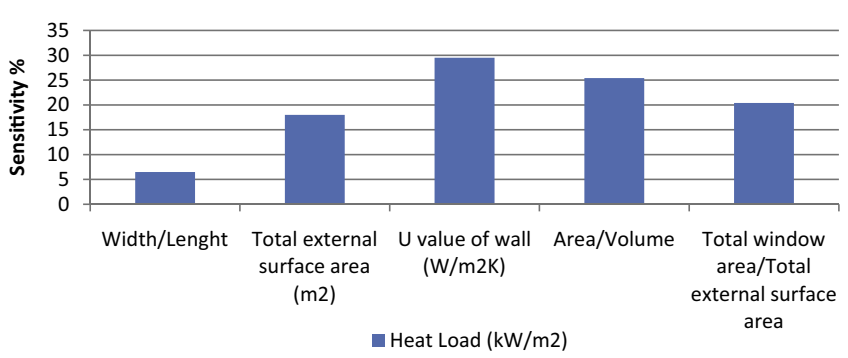

Fig. 12. Results of sensitivity analysis with 5 inputs.

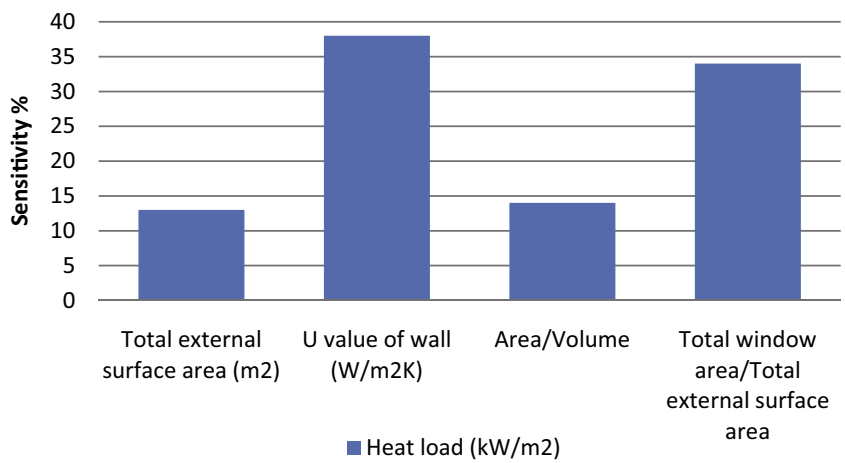

Fig. 13. Results of sensitivity analysis with 4 inputs.

buildings. The determination of the best learning algorithm and optimal number of neurons for the heat load are shown in Table 2. The highest $R^{2}=98.5 \%$ and the lowest MSE of $2.49 \times 10^{-6}$ and MAPE of 4 were obtained with a structure of (LM) learning algorithm and 4-7-5-1 number of neurons.

The comparison of KEP-IYTE-ESS and ANN results of building heat load in the training set is given in Figs. 6 and 7. The graphics clearly show that the training of the model was successfully accomplished since the model fits with software data. This case is also supported by the fact that $R^{2}$ values were very close to 1 [14,31,32,34,51].

When checking the normality assumption for error terms in a model, one often makes use of a normal probability of the residuals. A normal probability plot is a plot of ordered sample data versus their estimated values if the sample came from a normal population. A strong linear trend in the plot is indicative of normality [55]. Fig. 8 indicates linearity of the errors for building heat load prediction.

The histogram of the residuals can be used to check whether the variance is normally distributed. A symmetric bell-shaped histogram which is evenly distributed around zero indicates that the normality assumption is likely to be true [55]. The error of building heat load was normally distributed as shown in Fig. 9.

The trained model was tested with a group of 45 data sets and the results are provided in Figs. 10 and 11. The figures indicate that the predicted values of the model has close match with the software outputs with an $R^{2}$ of $97.7 \%$.

\subsection{Sensitivity analysis}

Sensitivity analysis of the model is displaced in Fig. 12. First, 5 input parameters were analyzed to find and eliminate some irrelevant input(s). The figure indicates that $\mathrm{A} / \mathrm{V}$ ratio, total external surface area, $U$ value of the walls and TWA/TESA ratio have the highest effect around $20 \%$ on the heat load of buildings while $\mathrm{W} / \mathrm{L}$ ratio was found to be the least influencing parameter for the model. The $R^{2}$ of the model was obtained as 0.937 . Then, the sensitivity analysis was re-applied after eliminating the least effective parameter $(\mathrm{W} / \mathrm{L}$ ratio) and the results are shown in Fig. 13. The figure indicates that $U$ value dominates the heat load with more than $35 \%$ sensitivity followed by total external surface area (approximately $10 \%$ sensitivity). Comparing to the previous model, $R^{2}$ was improved to 0.977 which was the best model.

\section{Conclusions}

The purpose of this study is to predict the heat load of existing buildings by constructing an ANN model and compare the results with a building energy simulation tool called KEP-IYTE-ESS developed by Izmir Institute of Technology. The input data of the models were obtained from 148 existing residential buildings including 2136 apartments located in Izmir-Turkey. Input parameters fed the model were $\mathrm{W} / \mathrm{L}$ ratio, overall heat transfer coefficient of the walls $(U), \mathrm{A} / \mathrm{V}$ ratio, TWA/TESA ratio and total external surface area. In ANN model, while 103 building data were used for training, the rest served to test the model. The best results were obtained for 7 and 5 neurons in two hidden layers with LM learning algorithm.

The heat load estimation of the buildings using ANN model was successfully accomplished with a correlation coefficient $\left(R^{2}\right)$ of $97.7 \%$. Sensitivity analysis was performed on the model in order to determine the effect of each input parameters on the model output. The most influencing parameters on heat load estimation were obtained to be $U$ value and total external surface area.

Although, regression models and dynamic building energy simulation software are effective and accurate, in practice, they have some difficulties. Regression models require significant effort and time while the performance of this approach is not robust enough when the data set becomes very large. The dynamic building energy simulation software require detailed building and environmental parameters as input data. However, to obtain these parameters for existing buildings are generally difficult and time consuming, sometimes are not possible. The lack of existing input data will lead to a low accurate simulation. Besides, operating the simulation tools normally require tedious expert work, making it difficult to perform.

This study exhibits that ANN models can predict heat load of the buildings with a good accuracy $\left(R^{2}=97.7 \%\right)$ using only four input data. Except $U$ value, the rest are geometrical properties which can easily be measured if the architectural projects of the buildings are not available. $U$ value can simply be calculated either thermo-physical properties of the wall materials or measuring surface and outdoor temperatures. Comparing the number of input data required for simulation software, ANN models suggest a simple model with a high accuracy. Besides, ANNs require less expertise and effort compared to the other approaches. This approach can also be useful for new and existing buildings having architectural projects with its simplicity and speed of calculation.

An accurate, simple and fast way to obtain building energy performance data is crucial for the countries like Turkey who has released the regulations but not yet determined the energy performance data of its existing building stock.

\section{Acknowledgements}

The Scientific and Technological Research Council of Turkey (TÜBiTAK) funded this research and their contribution is gratefully acknowledged (Project Number: 109M450). The authors would like to thank to Prof. Dr. Gokmen Tayfur for his valuable comments on the manuscript.

\section{References}

[1] H.X. Zhao, F. Magoules, A review on the prediction of building energy consumption, Renewable and Sustainable Energy Reviews 16 (3) (2012) 3586-3592. 
[2] EnergyPlus 7, US DOE, 2011.

[3] DOE, 2.2 Version 47d Edition, James J. Hirsch \& Associates (JJH), 2009

[4] T. Catalina, J.Virgone, E. Blanco, Development and validation of regression models to predict monthly heating demand for residential buildings, Energy and Buildings 40 (2008) 1825-1832.

[5] G.K.F. Tso, K.K.W. Yau, A study of domestic energy usage patterns in Hong Kong, Energy 28 (2003) 1671-1682.

[6] F. Egelioglu, A.A. Mohamad, H. Guven, Economic variables and electricity consumption in Northern Cyprus, Energy 26 (2001) 355-362.

[7] K.K. Wan, D.H.W. Li, D. Lui, J.C. Lam, Future trends of building heating and cooling loads and energy consumption in different climates, Building and Environment 46 (2011) 223-234.

[8] I. Korolija, Y. Zhang, L.M. Halburd, V.I. Harby, Regression models for predicting UK office building energy consumption from heating and cooling demand, Energy and Buildings 59 (2013) 214-227.

[9] J.S. Hygh, J.F. DeCarolis, D.B. Hill, S.R. Ranjithan, Multivariate regression as an energy assessment tool in early building design, Building and Environment 57 (2012) 165-175.

[10] T. Catalina, V. Iordache, B. Caracaleanu, Multiple regression models for fast prediction of the heating energy demand, Energy and Buildings 57 (2013) 302-312

[11] S. Paudel, M. Elmtiri, W.L. Kling O. Le Corre, Pseudo dynamic transitional modeling of building heating energy demand using artificial neural network, Energy and Building 70 (2014) 81-93.

[12] SAS, SAS Statistical Software Package, Version 6.12, SAS Institute Inc., Cary, NC, USA, 2005.

[13] SPSS, IBM SPSS Statistics, Version 22.0, SPSS Inc., USA, 2014.

[14] R. Kumar, R.K. Aggarwal, J.D. Sharma, Estimation of total energy load of building using Artificial Neural Network, Energy and Environmental Engineering 1 (2) (2013) 25-35

[15] TRNSYS 14.2, University of Wisconsin, Madison, WI, USA, 1996

[16] BDA 3.1, Lawrence Berkeley National Laboratory, University of California, USA, 1997.

[17] ESP-r, Version 2, Free Software Foundation Inc., Boston, USA, 1989.

[18] BLAST 3.0, Building Systems Laboratory, University of Illionis, USA, 1999.

[19] Bsim 2000, Danish Building Research Institute, Denmark, 2000.

[20] IDA, ICE Version 4.6, EQUA Solutions, Sweden, 2014

[21] D. Coakley, P. Raftery, M. Keane, A review of methods to match building energy simulation models to measured data, Renewable and Sustainable Energy Reviews 37 (2014) 123-141.

[22] M. Manfren, N. Aste, R. Moshksar, Calibration and uncertainty analysis for computer models - a meta-model based approach for integrated building energy simulation, Applied Energy 103 (2013) 627-641.

[23] A.H. Neto, F.A.S. Fiorelli, Comparison between detailed model simulation and artificial neural network for forecasting building energy consumption, Energy and Buildings 40 (2008) 2169-2176.

[24] Y. Heo, R. Choudhary, G. Augenbroe, Calibration of building energy models for retrofit analysis under uncertainty, Energy and Buildings 47 (2012) 550-560.

[25] A. Boyano, P. Hernandez, O. Wolf, Energy demands and potantial savings in European office buildings: case studies based on EnergyPlus simulations, Energy and Buildings 65 (2013) 19-28.

[26] M.C. Katafygiotou, D.K. Serghides, Analysis of structural elements and energy consumption of school building stock in Cyprus: energy simulations and upgrade scenerios of a typical school, Energy and Building 72 (2014) 8-16.

[27] T. Maile, V. Bazjanac, M. Fischer, A method to compare simulated and measured data to assess building energy performance, Building and Environment 56 (2012) 241-251.

[28] F. Karlsson, P. Rohdin, P.L. Persson, Measured and predicted energy demand of a low energy building: important aspects when using building energy simulation, Building Services Engineering Research and Technology 28 (2008) 223-235.

[29] H. Scofield, Do LEED-certified buildings save energy? Not really. ..., Energy and Building 41 (2009) 1386-1390.

[30] S.L. Wong, K.K.W.Wan, T.N.T. Lam, Artificial neural networks for energy analysis of office buildings with daylighting, Applied Energy 87 (2010) 551-557.

[31] B.B. Ekici, U.T. Aksoy, Prediction of building energy consumption by using artificial neural networks, Advanced Engineering Software 40 (2009) 356-362.
[32] G. Mavromatidis, S. Acha, N. Shah, Diagnotic tools of energy performance for supermarkets using Artificial Neural Network algorithms, Energy and Buildings 62 (2013) 304-314.

[33] S.K. Kwok, Y.E.W.M. Lee, A study of the importance of occupancy to building cooling load in prediction by intelligent approach, Energy Conversion and Management 52 (2011) 2555-2564.

[34] Q. Li, Q.L. Meng, J.J. Cai, H. Yoshino, A. Mochida, Predicting hourly cooling load in the building: a comparison of support vector machine and different artificial neural networks, Energy Conversion and Management 50 (2009) 90-96.

[35] S. Pandey, D.A. Hindoliya, R. Mod, Artificial Neural Network for prediction of cooling load reduction using green roof over building in sustainable city, Sustainable Cities and Society 3 (2012) 37-45.

[36] A.P. Melo, D. Costola, R. Lamberts, J.L.M. Hensen, Development of surrogate models using artificial neural network for building shell energy labelling, Energy Policy 69 (2014) 457-466.

[37] J.S. Chou, D.K. Bui, Modeling heating and cooling loads by artificial intelligence for energy efficient building design, Energy and Buildings (2014), http://dx.doi.org/10.1016/j.enbuild.2014.07.036 (in press).

[38] FORTRAN, ISO/IEC 1539-1, IBM, 2010

[39] MATLAB, Version 2008 ed., The Mathworks, 2008.

[40] S. Kaligirou, G. Florides, C. Neocleous, C. Shizas, Estimation of Daily Heating and Cooling Loads Using Artificial Neural Networks, In: World Congress, Napoli, September, 2001, http://ktisis.cut.ac.cy/bitstream/10488/883/1/ C41CLIMA2001.pdf (accessed 13.05.14).

[41] KEP-SDM, Dwelling Energy Performance-Standart Assessment Procedure, Chambers of Mechanical Engineers, Izmir, Turkey, 2008.

[42] T. Kazanasmaz, İ. Erlalelitepe Uygun, G. Gökçen Akkurt, C. Turhan, K.E. Ekmen, On the relation between architectural considerations and heating energy performance of Turkish residential buildings in Izmir, Energy and Buildings 72 (2014) 38-50.

[43] Turkish Institution of Standarts, TS825 - the Thermal Insulation Requirements for Buildings, Ankara, 1999 (in Turkish).

[44] G. Manioglu, Z. Yilmaz, Energy efficient design strategies in the hot dry area of Turkey, Building and Environment 43 (2008) 1301-1309.

[45] J. Neymark, R. Judkoff, G. Knabe, H.T. Le, M. Durig, A. Glass, et al., Applying the building energy simulation test (BESTEST) diagnostic method to verification of space conditioning equipment models used in whole-building energy simulation programs, Energy and Buildings 34 (2002) 917-931.

[46] G. Gökçen Akkurt, C.D. Sahin, S. Takan, Z.D. Arslan, Testing a simplified building energy simulation program via building energy simulation test (BESTTEST), in: CLIMAMED 7th Mediterranean Congress of Climatization, Istanbul, Turkey, October, 2013, pp. 49-57.

[47] K. Kavaklioglu, H. Ceylan, H.K. Ozturk, C.E. Canyurt, Modeling and prediction of Turkey's electricity consumption using Artificial Neural Networks, Energy Conversion and Management 50 (2009) 2719-2727.

[48] M.N. Inanici, F.N. Demirbilek, Thermal performance optimization of building aspect ratio and south window size in five cities having different climatic characteristics of Turkey, Building and Environment 35 (2000) 41-52.

[49] R. Pachedo, J. Ordonez, G. Martinez, Energy efficient design of building: a review, Renewable and Sustainable Energy Reviews 16 (6) (2012) 3559-3573.

[50] L.P. Wang, J. Gwilliam, P. Jones, Case study of zero energy house design in UK, Energy and Buildings 41 (2009) 1215-1222.

[51] Y.O. Ozgoren, S. Cetinkaya, S. Saridemir, A. Cicek, F. Kara, Predictive modeling of performance of a helium charged Stirling engine using an artificial neural network, Energy Conversion and Management 67 (2013) 357-368.

[52] V.M.P. Antognetti, Neural Networks, Concepts Applications and Implementations, Prentice Hall, New Jersey, USA, 1991.

[53] S.F. Song ZZ. Lu, H.W. Qiao, Subset simulation for structural reliability sensitivity analysis, Reliability Engineering and System Safety 94 (2009) 658-665.

[54] T. Kazanasmaz, M. Gunaydın, S. Binol, Artificial neural networks to predict daylight illuminance in office buildings, Building and Environment 44 (8) (2009) $1751-1757$.

[55] D. Ruppert, Statistics and Finance: An introduction, Springer, New York, USA, 2004. 